\title{
Cytokine and adhesion molecule expression in the minor salivary glands of patients with Sjögren's syndrome and chronic sialoadenitis
}

\author{
Alberto Cauli, Ghada Yanni, Costantino Pitzalis, Steven Challacombe, Gabriel S Panayi
}

\begin{abstract}
Objective-To investigate the role of cytokines and cell adhesion molecules in the pathogenesis of Sjögren's syndrome (SS).

Methods-Using an indirect immunoperoxidase technique we assessed the expression of the cytokines interleukin-1

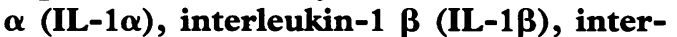
leukin-8 (IL-8), transforming growth factor $\beta$ (TGF $\beta$ ) and granulocyte macrophage colony stimulating factor (GM-CSF), of the adhesion molecules intercellular adhesion molecule-1 (ICAM-1), lymphocyte function associated antigen-1 (LFA-1), the activated molecular form of LFA-1 (NKI-L16), CD2, and LFA-3, and of a panel of cellular markers in the minor salivary glands.
\end{abstract}

Results-In SS and chronic sialoadenitis (CS), the ductal epithelial cells and acini expressed all the cytokines examined. The percentage of glandular mononuclear cells which stained positive for cytokines did not differ significantly between SS and CS. NKI-L16 was detected on 33.6 (SD $10 \cdot 1) \%$ and $15 \cdot 3(4 \cdot 3) \%$ of LFA-1 cells in SS and CS, respectively (p<0.002).

Conclusion-SS and CS did not differ in the pattern of cytokines examined. The characteristic cell clustering seen in the salivary glands in SS may be caused by the upregulation of NKI-L16.

(Ann Rheum Dis 1995; 54: 209-215)

Rheumatology Unit, Division of Medicine, United Medical and Dental Schools, Guy's Hospital, London, United Kingdom A Cauli

G Yanni

C Pitzalis

G S Panayi

Department of Oral

Medicine and

Pathology

$S$ Challacombe

Correspondence to:

Professor G S Panayi,

Rheumatology Unit,

Department of Medicine,

Fourth floor,

Hunt's House,

Guy's Hospital,

St Thomas Street

London SE1 9RT,

United Kingdom.

Accepted for publication

14 October 1994
Cytokines have been implicated in the pathogenesis of many inflammatory lesions. Previous studies, applying immunohistochemical techniques to the salivary glands of patients with SS, demonstrated that interferon gamma (IFN $\gamma$ ) was extensively expressed in the acini, ducts, and MNCs, but only $2.4 \%$ of infiltrating cells expressed interleukin-2 (IL-2). ${ }^{67}$ This was further confirmed by in situ hybridisation and the reverse transcriptase polymerase chain reaction (RT-PCR), ${ }^{8-10}$ in which mRNA for IFN $\gamma$ and IL-2 was detected in the salivry glands of all patients studied, while interleukin-4 (IL-4) was absent. ${ }^{8}$ These observations suggest continuing $T$ cell activation of the Th 1 cell type in the SS lesions, as reflected by the local production of IL-2 and IFN $\gamma$. Furthermore, biopsies of salivary glands from SS patients with extensive lymphoid infiltrates contained mRNA for IL-2 and IFN $\gamma$, while biopsies with few lymphoid infiltrates had large amounts of transforming growth factor $\beta$ (TGF $\beta) .{ }^{10}$ It was suggested, therefore, that the greater concentrations of TGF $\beta$ in minimal lesions may play a role in downregulating the inflammatory process. Support for this hypothesis comes from a mouse model in which disruption of the TGF $\beta$ gene by homologous recombination in murine embryonic stem cells makes the animals unable to mount an efficient anti-inflammatory response. The salivary glands of these mice were characterised by a periductal lymphoplasmacytic infiltrate not unlike that associated with SS. ${ }^{11}$

Chronic sialoadenitis (CS) is a non-specific inflammatory process of the salivary glands characterised by a sparse diffuse MNC infiltrate in the gland leading to glandular atrophy with secondary signs and symptoms of dry mouth, but not the presence of autoantibodies. Thus this disease is the ideal control for immunopathological studies in SS. We decided, therefore, in the first instance to investigate the expression of cytokines such as TGF $\beta, \mathrm{IL}-1 \alpha, \mathrm{IL}-1 \beta, \mathrm{IL}-8$ and granulocyte macrophage colony stimulating factor (GM-CSF) in SS and CS to see if these two conditions could be distinguished. We also examined salivary glands from five healthy normal control subjects. In order to clarify the typically different (focal versus diffuse) distribution and organisation of the MNC infiltrate in SS and CS, we then studied the expression of specific adhesion molecules (lymphocyte function associated antigen-1 (LFA-1)/intercellular adhesion molecule-1 (ICAM-1) and CD2/LFA-3) involved in homo- and heterotypic cluster formation. Finally, we examined the expression of an activation dependent epitope of the LFA-1 
molecule recognised by the monoclonal antibody (MAb) NKI-L16. ${ }^{12}$

\section{Patients and methods}

PATIENTS

We studied six patients with definite SS (four primary and two secondary with rheumatoid arthritis; mean age 64.6 (range $40-79$ years; all female) who fulfilled the American College of Rheumatologists criteria and European criteria for $\mathrm{SS}^{2}{ }^{3}$ This group was characterised by symptoms and signs of ocular and oral involvement, and the presence of antinuclear antibodies, and SS-A and SS-B antibodies. Four of five patients tested were rheumatoid factor positive and all demonstrated a typical periductal infiltrate on histological analysis of the minor salivary glands. We also studied six patients with CS (mean age 58.3 range 57-76 years; five females and one male) with sicca syndrome and the histopathological features of CS. This group was characterised by oral involvement (xerostomia), no signs or symptoms of lachrymal involvement, absence of autoantibodies (rheumatoid factor, SS-A and SS-B) and the presence of a lymphocytic infiltrate in the salivary glands. Five biopsies from healthy volunteers were also studied.

\section{TISSUE PREPARATION AND STAINING}

Biopsies containing at least two foci per $4 \mathrm{~mm}^{2}$ were obtained from minor salivary glands from the midline of the lower lip and embedded in optimal temperature cutting compound (OCT, Miles, CA) and snap frozen in isopentane and liquid nitrogen. Samples were stored at $-70^{\circ} \mathrm{C}$ until sectioned for immunohistological staining. Sections $5 \mu \mathrm{m}$ thick were cut with a cryostat (Leitz) at $-22^{\circ} \mathrm{C}$. Sequential sections were mounted on poly-L-lysine coated slides and dried overnight at room temperature. Sections were fixed in acetone for 10 minutes, wrapped in tin foil, and stored at $-70^{\circ} \mathrm{C}$ until further use.

Cytokines and cellular antigens were determined by an indirect immunoperoxidase technique. The MAbs used to determine cellular content were OKT3, OKT4, OKT8, (anti-CD3, anti-CD4, anti-CD8, respectively; ATCC, USA), B-Ly1, and EBM11 (antiCD20, a B cell marker and anti-CD68, a macrophage marker, respectively; Dako laboratories, Copenhagen, Denmark). Antifactor VIII related antigen (Dako) was used to stain endothelial cells. The MAbs used to determine cytokine expression were anti-IL-1 $\alpha$ (gift of Dr R Thorpe, NIBSC, Potters Bar), anti-IL-1 $\beta$ (gift of Dr D Boraschi, Italy), antiGM-CSF (gift of Dr K Ruedi, Sandoz, Basel, Switzerland), anti-IL-8 (gift of Dr M Ceska, Vienna) and anti-TGF $\beta$ (gift of Dr Feldman, Genentech, USA). The MAbs used to detect the adhesion molecules were anti-LFA-1 (TS1/22 hybridoma clone, gift of Dr T Springer, USA), NKI-L16 (gift of Prof Figdor, Netherland), anti-ICAM-1 (gift of Dr D Haskard, London, $\mathrm{UK}$, anti-CD2 and anti-LFA3 (Becton Dickinson, CA, USA).
Briefly, the salivary gland tissue sections were incubated for 10 minutes with a 1:20 dilution of normal rabbit serum in a humidified chamber at room temperature. The sections were then incubated with the primary MAbs, at appropriate dilutions in phosphate buffer saline (PBS) for two hours. The excess $\mathrm{MAb}$ was removed by washing with PBS. The second antibody, horseradish peroxidase conjugated rabbit anti-mouse (Dako laboratories, Copenhagen, Denmark) diluted in PBS at 1:100, was added and sections were incubated for 30 minutes. After rinsing with PBS the sections were developed in a solution of diaminobenzidine tetrahydrochloride $0.7 \mathrm{mg} / \mathrm{ml}$, and counterstained with haematoxylin. Finally, sections were dehydrated by transferring through alcohol and CNP30, and mounted in DPX.

Negative control staining was performed on all salivary gland specimens studied, following an identical procedure except that incubation with the primary MAb was omitted; no staining was noted in these sections. Tonsil tissue was used as a positive control. Other controls included MOPC21 - a non-immune mouse IgG1 myeloma protein MOPC21, with an isotype similar to the cytokine MAbs used, which was used at equivalent protein concentration.

All comparisons between specimens were made with data derived from the same staining run.

\section{CONFIRMATION OF CYTOKINE}

IMMUNOREACTIVITY

The specificity of the cytokine MAbs has been extensively studied ${ }^{13}$ and demonstrated by the providers of these reagents (IL- $1 \alpha,{ }^{14} \mathrm{IL}-1 \beta,{ }^{15}$ GM-CSF, ${ }^{16}$ IL-8 ${ }^{17}$ and TGF $\left.\beta^{18}\right)$. The specificity of the binding of these antibodies to salivary gland tissue was confirmed by: staining with cytokine $\mathrm{MAb}$ (staining was concentration dependent); using an irrelevant antibody, MOPC21, at equivalent protein concentration; comparing the pattern and degree of staining of different MAbs for the same cytokine product on salivary gland and tonsil which yielded the same pattern of staining; and verifying the increased cytokine production by phytohaemagglutinin stimulated versus resting peripheral blood MNCs.

\section{MICROSCOPIC EVALUATION}

All microscopic evaluations were performed in a coded fashion by one observer (AC) who was blinded to the name of the patients and diagnosis. To rule out intra-observer variation, the samples were randomised, recoded, and read on a second occasion. (No significant differences were demonstrated between the two readings.) Samples were also assessed by another investigator (GY) to estimate interobserver variation. (No significant differences were found between the two investigators.)

NUMBER OF INFILTRATING CELLS

For each patient, the total number of infiltrating cells was estimated by counting all 


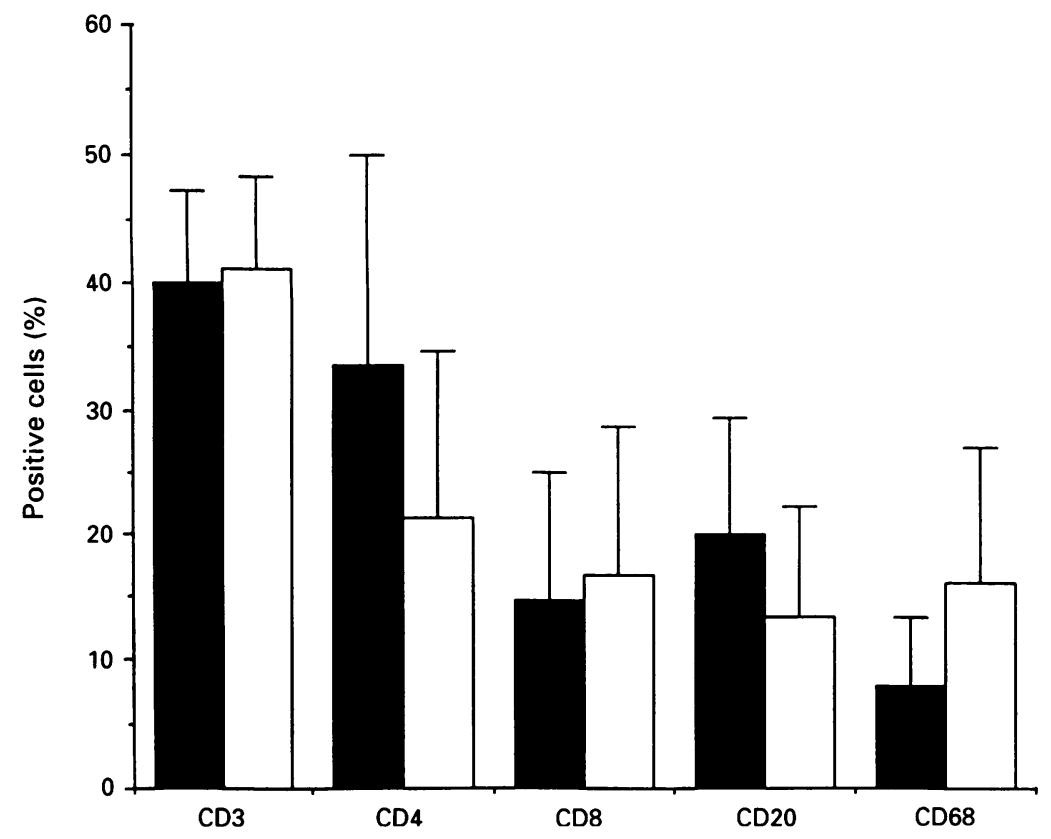

Figure 1 Phenotypic analysis of the mononuclear cellular infiltrate in Sjögren syndrome (G) and chronic sialoadenitis ( $\square$ ). the cells throughout the minor gland biopsied and expressing the results per $\mathrm{mm}^{2}$.

CELL SUBSETS

The number of cells staining positively for a particular cell marker was counted in a total of 500 cells, and the results expressed as a percentage.

CYTOKINE STAINING

Cytokine expression was assessed in three areas of the salivary glands: infiltrating cells, ducts, and acini. In the infiltrate, cytokine staining was assessed as a percentage of positively staining cells in a total of 500 cells, while in the acini and ducts the intensity of staining was estimated by devising a scale of $0-8$, where $0=$ no staining and $8=$ maximal staining.

\section{VASCULAR PROLIFERATION}

Vascular proliferation was estimated by counting the number of blood vessels staining with factor VIII and expressing the results per $\mathrm{mm}^{2}$.

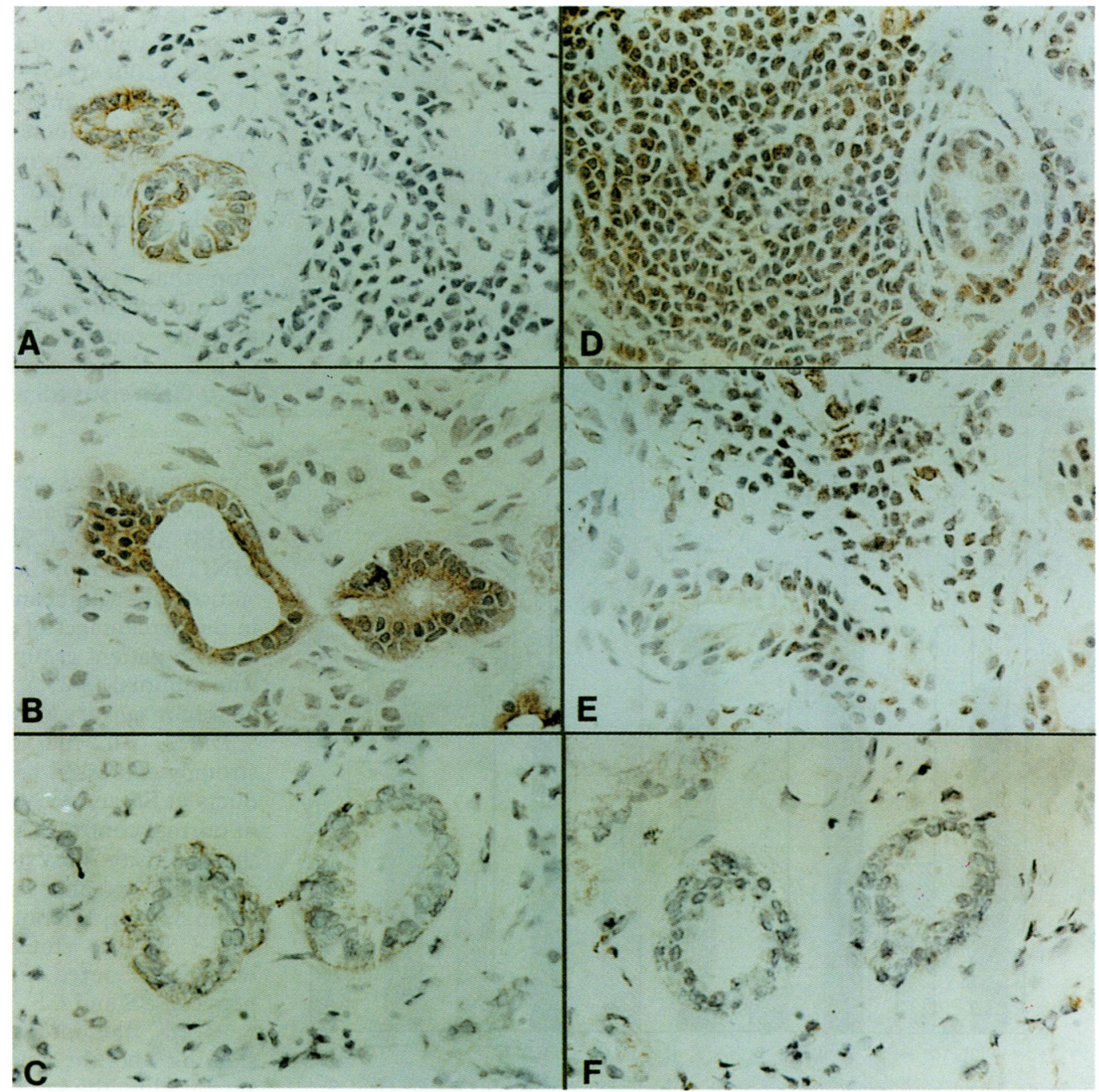

Figure 2 Interleukin-8 staining in Sjögren's syndrome $(A)$, chronic sialoadenitis $(B)$, and normal controls $(C)$ Transforming growth factor beta staining in Sjögren's syndrome (D), chronic sialoadenitis $(E)$, and normal controls. $A, B, D, E: 10 \mathrm{~mm}$ represents $34.5 \mu \mathrm{m} ; C, F: 10 \mathrm{~mm}$ represents $19.5 \mu \mathrm{m}$. 
ADHESION MOLECULES

Adhesion molecule expression was assessed in the three areas of all salivary gland tissue sections and their distribution analysed. For the expression of NKI-L16, the number of NKI-L16 positive cells in a total number of 500 LFA-1 positive cells was counted and the results expressed as a percentage.

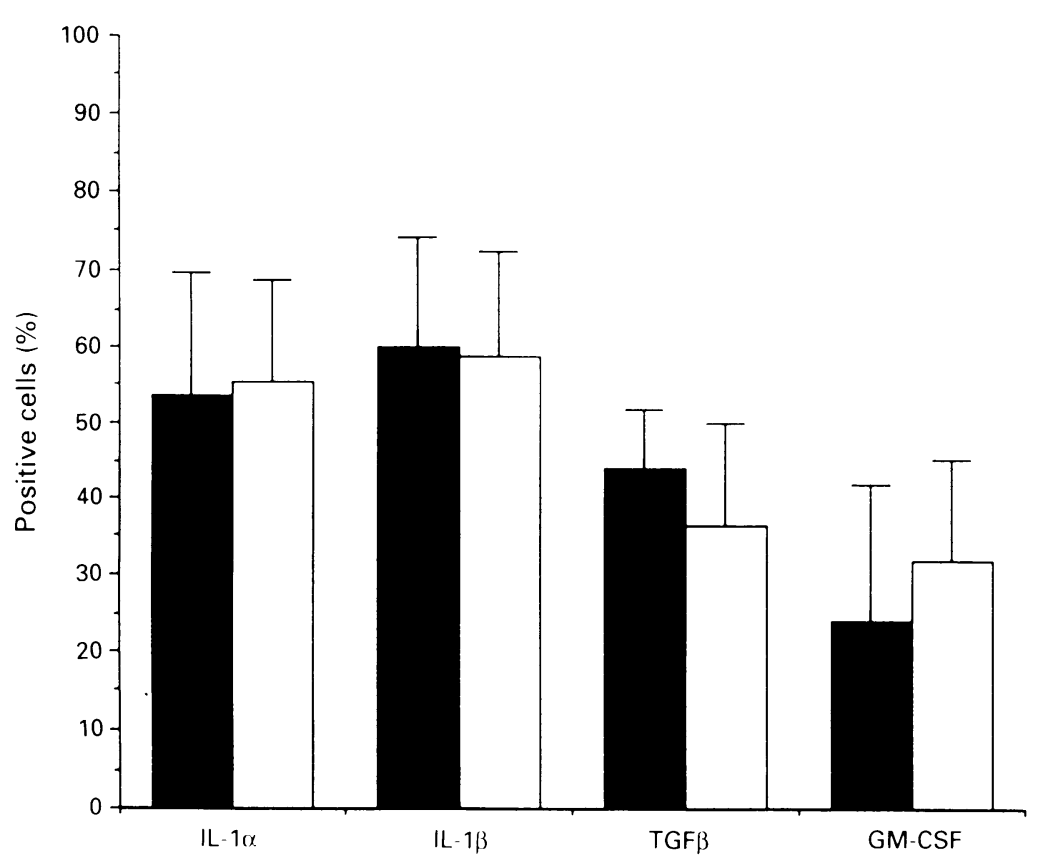

Figure 3 Percentage of staining cells for the cytokines interleukin-1 $\alpha(I L-1 \alpha)$ interleukin-1 $\beta(I L-1 \beta)$, transforming growth factor $\beta(T G F \beta)$ and granulocyte macrophage colony stimulating factor (GM-CSF) in the mononuclear cellular infiltrate of the minor salivary glands of patients with Sjögren's syndrome (-) and chronic sialoadenitis ( $\square$ ).

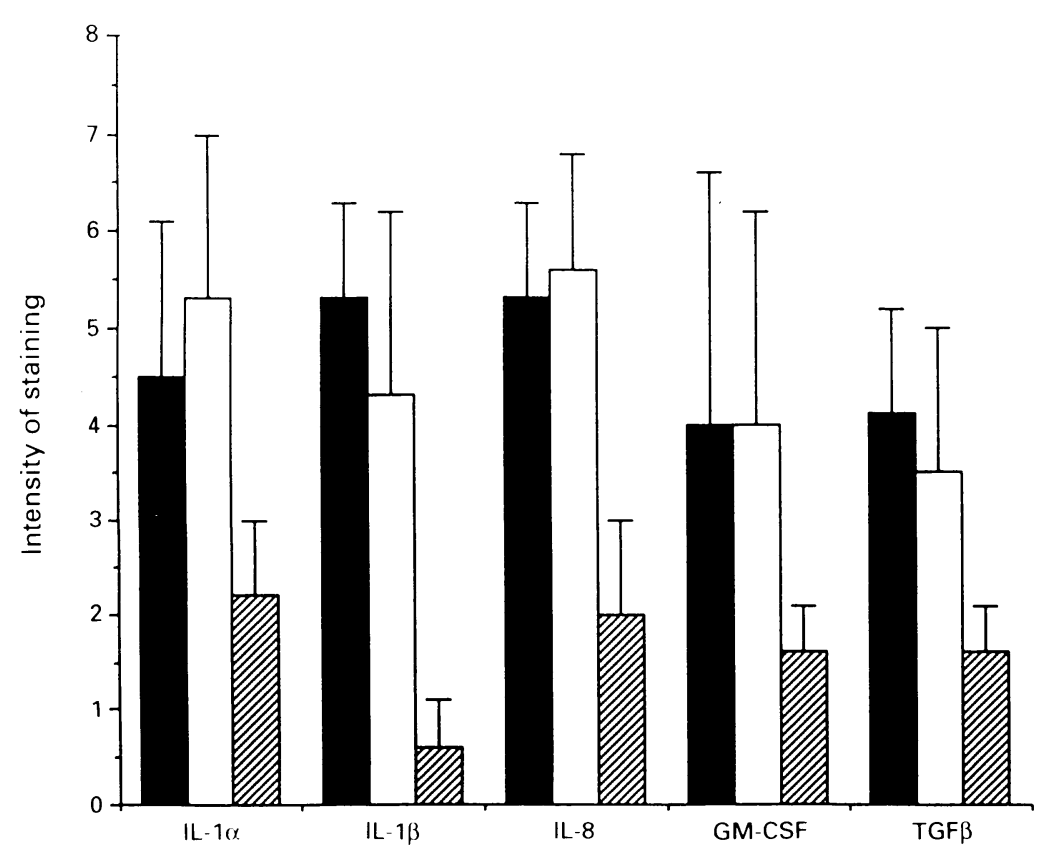

Figure 4 Intensity of staining of the cytokines interleukin-1 $\alpha(I L-1 \alpha)$ interleukin-1 $\beta$ (IL-1 $\beta$ ), interleukin-8 (IL-8), granulocyte macrophage colony stimulating factor (GM-CSF) and transforming growth factor $\beta(T G F \beta)$ in the ducts of the minor salivary glands of patients with Sjögren's syndrome (U) or chronic sialoadenitis ( $\square$ ), and normal controls ( $E A)$.
STATISIICS

Results are expressed as mean (SD). Histological scores in the three different groups were compared using the Mann-Whitney test.

\section{Results}

HISTOL OGICAL FEATURES AND CELLULAR COMPOSITION

Minor salivary gland biopsies from patients with SS demonstrated typical focal lymphocytic clusters of more than 50 cells per focus. In contrast, in CS the infiltrating cells were randomly scattered throughout the gland. No infiltrating cells were observed in normal controls. Significantly greater numbers of infiltrating cells per $\mathrm{mm}^{2}$ of tissue were seen in SS $\left(1717 \cdot 1(1083 \cdot 3)\right.$ cells $\left./ \mathrm{mm}^{2}\right)$ compared with CS $\left(537 \cdot 0 \quad(584 \cdot 2)\right.$ cells $\left./ \mathrm{mm}^{2}\right)$ $(\mathrm{p}<0.031)$. Phenotypic analysis of the infiltrating cells in the two pathological groups revealed no statistically significant differences (fig 1) It is worth noting however, that the $\mathrm{CD} 4: \mathrm{CD} 8$ ratio was greater in SS $(2 \cdot 8)$ compared with CS $(1 \cdot 8)$, reflecting the greater number of $\mathrm{CD} 4$ cells seen in SS $\left(33.6(16.4)\right.$ cells $\left./ \mathrm{mm}^{2}\right)$ compared with CS $\left(21.2(13.5)\right.$ cells $\left./ \mathrm{mm}^{2}\right)$. The number of CD8 cells was similar in the two groups $(14.6(10 \cdot 3)$ and $16.6(12 \cdot 1) \quad$ cells $/ \mathrm{mm}^{2}$, respectively). Greater numbers of CD20 cells were counted in SS $\left(20.0(9.5)\right.$ cells $\left./ \mathrm{mm}^{2}\right)$ than in CS $(13.38 .9)$ cells $\left./ \mathrm{mm}^{2}\right)$. There was a tendency to greater numbers of CD68 cells in CS $\left(16 \cdot 2(10.9)\right.$ cells $\left./ \mathrm{mm}^{2}\right)$ compared with SS $\left(8.0(5.4)\right.$ cells $\left./ \mathrm{mm}^{2}\right)$. The number of blood vessels per $\mathrm{mm}^{2}$ of tissue in SS (134.1 (21.8) vessels $/ \mathrm{mm}^{2}$ ) was not significantly different from that in CS $\left(129.5(10.4)\right.$ vessels $\left./ \mathrm{mm}^{2}\right)$, but in both diseases more blood vessels were present compared with normal subjects $\left(100.5(10.8)\right.$ vessels $\left./ \mathrm{mm}^{2}\right) \quad(p=0.015$ and $\mathrm{p}=0.004$ versus $S S$ and CS, respectively).

\section{CY TOKINE EXPRESSION}

Mononuclear cellular infiltrate. IL- $1 \alpha$, IL-1 $\beta$, TGF $\beta$ and GM-CSF were expressed in the MNC infiltrate of both SS and CS (fig 2). No statistically significant differences were noted in the percentages of positively staining cells in the two patient groups (fig 3). IL-8 expression was minimal $(<2 \%)$ in the MNC infiltrate of all minor salivary glands examined.

Ducts. All the cytokines studied were strongly expressed in the epithelial cells of the ducts in SS and CS, but at a much lower level in normal controls. As can be seen in figure 4, the intensity of cytokine staining was significantly greater in the disease groups compared with control subjects, except for GM-CSF. No statistically significant differences were noted in the intensity of staining between SS and CS. There was no correlation between the intensity of ductal cytokine staining and the number of infiltrating cells surrounding the same duct (data not shown).

Acini. All cytokines studied were expressed in the acini of SS, CS, and normal controls. The intensity of cytokine staining in the acini 


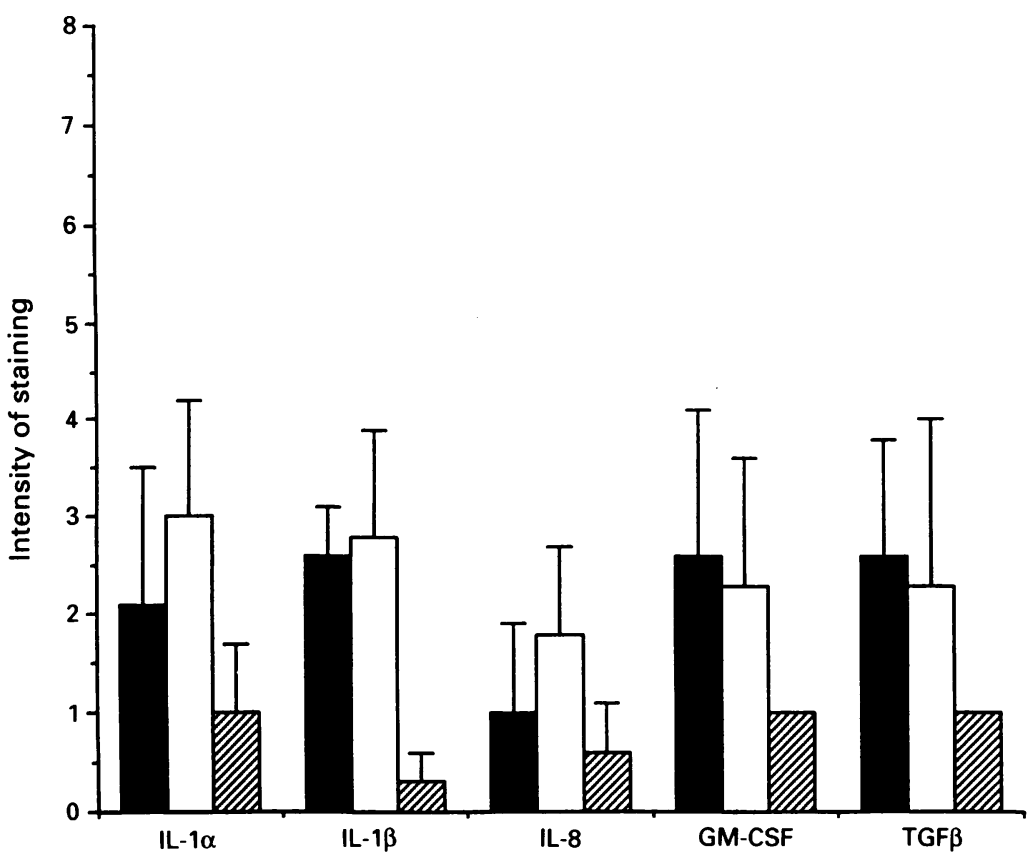

Figure 5 Intensity of staining of the cytokines interleukin-1 $\alpha(I L-1 \alpha)$ interleukin-1 $\beta$

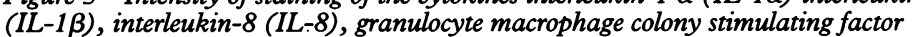
(GM-CSF) and transforming growth factor $\beta$ (TGF $\beta$ ) in the acini of the minor salivary glands of patients with Sjögren's syndrome ( $\square$ ) or chronic sialoadenitis ( $\square$ ), and normal controls ( $\square)$.
LFA-3 was expressed by acini, ducts, blood vessels, and MNC in both SS and CS. ICAM1 was equally detected on blood vessels and MNC of both diseases. Likewise, LFA-1 and $\mathrm{CD} 2$, found on $\mathrm{MNC}$, were equally expressed in SS and CS. However, there was a striking difference in expression of NKI-L16, which was found on $33.6(10 \cdot 1) \%$ and $15.3(4 \cdot 3) \%$ of LFA-1 positive cells in SS and CS, respectively $(p<0.002)$ (fig 6$)$.

\section{Discussion}

In this study, analysis of cytokine expression by the infiltrating MNC revealed a similar percentage of IL- $1 \alpha$, IL-1 $\beta$, IL-8, GM-CSF and TGF $\beta$ positively staining cells in Sjögren's syndrome and chronic sialoadenitis. In both disease groups, the ducts and acini showed more intense staining of all cytokines examined compared with normal control subjects. No significant difference was noted between SS and CS. Acinar staining was less intense than ductal staining, supporting the previous suggestion of a minor role for the acinar epithelial cells compared with ductal epithelial cells in the salivary gland inflammatory process as shown by the expression of class II molecules in the epithelial cells. ${ }^{19-21}$ The HLA-DR upregulation may be caused by IFN $\gamma$ produced locally at the site of inflammation, as it is supported by the reported increase in IFNy staining in SS compared with controls. ${ }^{7}$ The aberrant expression of class II molecules could be related to the potential antigen presenting function of epithelial cells, as described in the epithelial cells from gut and respiratory mucosae, epidermis, and renal proximal tubules. ${ }^{22-24}$

The strong expression of TGF $\beta$ which we observed in the epithelial, acinar, and infiltrating cells clearly demonstrates that in SS

The adhesion molecules examined were detected at a similar level in both disease groups.

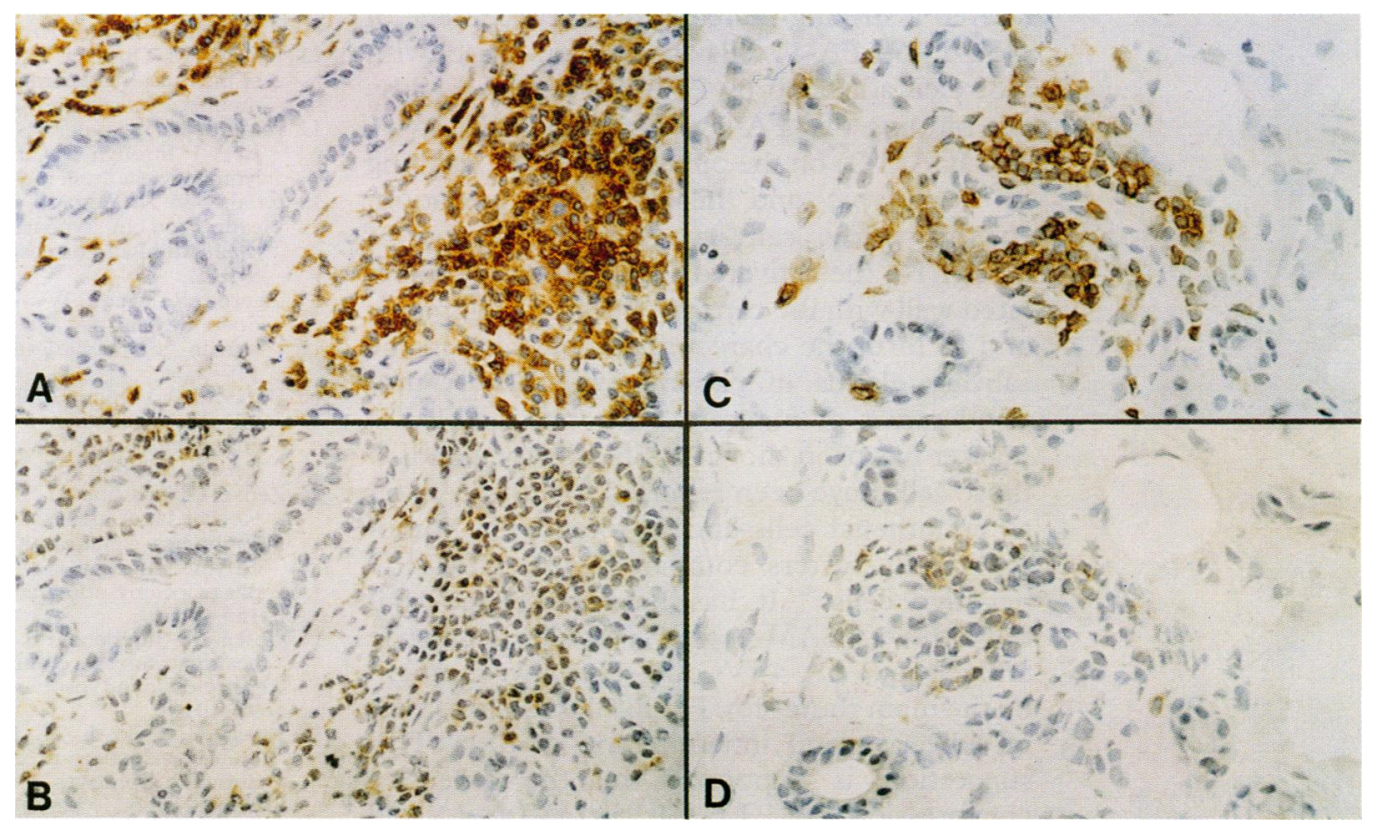

Figure 6 Staining of lymphocyte function associated antigen-1 (LFA-1) (A) and NKI-L16 (B) in the minor salivary glands of Sjögren's syndrome. Staining of LFA-1 (C) and NKI-L16 (D) in the minor salivary glands of chronic sialoadenitis. A-D: $10 \mathrm{~mm}$ represents $26.6 \mu \mathrm{m}$. 
there is no obvious TGF $\beta$ deficiency, but the activation state of TGF $\beta$ needs to be determined before any firm conclusions can be made. We did not demonstrate a correlation between the intensity of cytokine ductal staining and the number of surrounding MNCs. Our findings do not support other workers' observations of high expression of TGF $\beta$ in salivary glands of patients with SS with a minimal infiltrate compared with those with an intense infiltrate. ${ }^{10}$ It is possible that an unknown cytokine or other inflammatory mediator not examined in this work may be responsible for the periductal clustering of the infiltrating cells so typical in SS. Furthermore, it is necessary to study agonists and antagonists simultaneously, as the balance between these two may determine the nature of the disease.

Although there were greater numbers of CD4 and CD20 cells in SS compared with $\mathrm{CS}$, the difference did not reach statistical significance. However, the number of MNC throughout the SS salivary glands was three times greater. The organisation of MNC into foci in SS and sparsely diffuse infiltrates in CS was a striking difference between the two groups. In chronically inflamed non-lymphoid tissues, infiltrating lymphocytes form aggregates which are functionally and structurally similar to follicles found in lymph nodes or tonsil. The presence of focal lymphoid aggregates in the rheumatoid synovium is associated with greater production of cytokine by the synovial membrane..$^{25}$ In this study, we confirmed the presence of similar large lymphocyte aggregates in the salivary glands in SS, but were not able to show greater cytokine staining in the aggregates seen in SS.

The histological differences noted between SS and CS cannot be attributable to a greater degree of vascularisation in SS, as the numbers of blood vessels in SS and CS were similar. However, the differences may lie in the expression of adhesion molecules: we demonstrated a striking increase in the percentage of NKI-L16/LFA-1 cells in SS compared with CS. Cell adhesion by LFA-1 is established by the binding of LFA-1 to its ligands (ICAM-1 and ICAM-2) on the opposing cell ${ }^{26}{ }^{27}$ resulting in homotypic and heterotypic aggregation. In this study, salivary gland expression of NKI-L16, the activated LFA-1 epitope, correlated well with the capacity of cells to aggregate and to form the characteristic foci seen in the salivary glands of patients with SS. A preponderance of memory cells with CD45RO marker has been shown in SS salivary glands; ${ }^{28}$ these cells have been reported to adhere better to endothelial cells and to form large homotypic cell clusters compared with CD45RO negative cells. ${ }^{29}$ It has been suggested that the LFA-1/ICAM-1 and vascular leucocyte antigen-4 (VLA-4)/VCAM-1 pathways might be the main routes for $T$ cells to migrate to sites of salivary gland inflammation in SS. ${ }^{28}$ This suggestion is supported by the extensive coexpression of LFA-1 or VLA-4 and CD45RO by CD4 $T$ cell infiltrates adjacent to ICAM-1 or VCAM-1 postcapillary venules. These findings may point to a cytokine mediated upregulation of ICAM-1 and VCAM-1, facilitating the recruitment of LFA-1/NKI-L16 and VLA-4 cells and resulting in the infiltration of the salivary glands in SS.

In conclusion, this study shows that SS is characterised by periductal clustering of $\mathrm{MNC}$, while CS is characterised by a sparse infiltrate. No differences were noted in the subset of infiltrating $\mathrm{MNC}$ and cytokine expression in the salivary glands of the two patient groups, but there was upregulation of NKI-L16 in the MNC of SS, suggesting that the typical MNC aggregation seen in SS may be mediated by activation of LFA-1.

This study was supported by a core grant (U9) from the Arthritis and Rheumatism Council of Great Britain.

1 Fox R I, Howell F V, Bone R C, Michelson P E. Primary Sjögren's syndrome: clinical and immunopathologic features. Semin Arthritis Rheum 1984; 14: 77-105.

2 Fox R I, Robinson C A, Curd J G, Kozin F, Howell F V. Siögren's syndrome: proposed criteria for classification. Arthritis Rheum 1986; 29: 577-85.

3 Vitali C, Bombardieri S, Moutsopoulos H M et al. Preliminary criteria for the classification of Sjögren's Preliminary criteria for the classification

4 Talal N, Silvester R, Daniels T, Greenspan J, Williams R. $\mathrm{T}$ and $\mathrm{B}$ lymphocytes in peripheral blood and tissue lesions in Sjögren's syndrome. F Clin Invest 1974; 53: $180-9$.

5 Adamson T C, Fox R I, Frisman D M, Howell F V. Immunohistologic analysis of lymphoid infiltrates in primary Sjögren's syndrome using monoclonal antibodies. F Immunol 1983; 130: 203-8.

6 Fox R I, Theofilopoulos A N, Altman A. Production of interleukin 2 (IL 2) by salivary gland lymphocytes in Sjögren's syndrome. Detection of reactive cells by using antibody directed to synthetic peptides of IL 2 . F Immunol 1985; 135: 3109-15.

7 Rowe D, Griffiths M, Stewart J, Novick D, Beverley P C L, Isenberg D A. HLA class I and II, interferon, interleukin 2 , and the interleukin 2 receptor expression on labial biopsy specimens from patients with Sjog̈ren's labial biopsy specimens from patients with
syndrome. Ann Rheum Dis 1987 ; 46: 580-6.

8 Skopouli F N, Boumba D, Moutsopoulos H M. Cytokine mRNA expression in the labial salivary gland tissue from patients with primary Sjögren's syndrome. Clin Rheumatol 1993; 12: 18

9 Fox R I, Ando D, Abrams J, Kang H I. Characterization of cytokine mRNA transcripts in salivary gland biopsies from patients with Sjögren's syndrome (SS). Arthritis Rheum 1992; 35: S122.

10 Ogawa N, McGuff H, Dang H, Aufdermorte T, Talal N. Cytokine profiles of salivary glands from patients with Sjögren syndrome. Arthritis Rheum 1993; 36: S43.

11 Shull M M, Orrmsby I, Kier A B, et al. Targeted disruption of the mouse transforming growth factor- $\beta 1$ gene results in of the mouse transforming growth factor- $\beta 1$ gene results in
multifocal inflammatory disease. Nature 1992; 359: 693-9.

12 van Kooyk Y, Weder P, Hogervost F, et al. Activation of LFA-1 through a $\mathrm{Ca}^{2+}$ dependent epitope stimulate lymphocyte adhesion. F Cell Biol 1991; 112: 345-54

13 Farahat M N, Yanni G, Poston R, Panayi G S. Cytokine expression in synovial membranes of patients with rheumatoid and osteoarthritis. Ann Rheum Dis 1993; 52: $870-5$.

14 Thorpe $\mathrm{R}$, Wadh W A, Glearing A J H, Mahon B, Poole S. Sensitive specific immunoradiometric assay for human interleukin alpha. Lymphokine Res 1988; 7: 119-24.

15 Boraschi D, Volpini G, Villa L, et al. A monoclonal antibody to the Interleukin-1 beta peptide $163-171$ blocks
adjuvanticity but not pyrogenicity of IL-1b in vivo. adjuvanticity but not pyrogen

16 Zenke G, Strittmatter U, Tees R, Andersen E, Fagg B, Kocher H, Schreier M A. Cocktail of three monoclonal Kocher $\mathrm{H}$, Schreier $\mathrm{M}$ A. Cocktail of three monoclonal
antibodies significantly increases the sensitivity of an antibodies significantly increases the sensitivity of an enzyme immunoassay for human granulocyte macrophage colon $185-206$.

17 Ceska M. Interleukin-8 immunoreactivity in the skin of healthy subjects and patients with palmoplantar pustulosis and psoriasis. $\mathcal{f}$ Invest Dermatol 1992; 98: 96-101.

8 Lucas C, Bold L N, Fendly B M, et al. The autocrine production of transforming growth factor beta during lymphocyte activation. A study with a monoclonal antibody-based ELISA. F Immunol 1990; 145: 1415-22.

19 Speight P M, Cruchley A, Williams D M. Epithelial HLADR expression in labial salivary glands in Sjögren's syndrome and non-specific sialoadenitis. $f$ Oral Pathol Med 1989; 18: 178-83. 
20 Fox R I, Bumol T, Fantozzi R, Bone R, Schreiber R. Expression of histocompatibility antigen HLA-DR by salivary gland epithelial cells in Sjögren's syndrome. Arthritis Rheum 1986; 29: 1105-11.

21 Thrane P S, Halstensen T S, Haanaes H R, Brandtzaeg P. Increased epithelial expression of HLA-DQ and HLA-DP molecules in the salivary glands from patients with Sjögren's syndrome compared with obstructive sialoadenitis. Clin Exp Immunol 1993; 92: 256-62.

22 Mayer L, Shlien R. Evidence for function of la molecules on gut epithelial cells in man. $\mathcal{F} \operatorname{Exp}$ Med 1987; 166: 1471-83.

23 Grabbe S, Bruvers S, Gallo R L, Knisely T L, Nazareno R, Granstein $R$. Tumor antigen presentation by murine epidermal cells. F Immunol 1991; 146: 3656-61.

24 Hagerty D T, Allen P M. Processing and presentation of self and foreign antigens by the renal proximal tubule. f Immunol 1992; 148: 2324-30.
25 Yanni G, Whelan A, Feighery C, Symons J, Duff G, Bresnihan B. Contrasting levels of in vitro cytokine production by rheumatoid synovial tissue demonstrating different patterns of mononuclear cell infiltration. Clin Exp Immunol 1993; 93: 387-95.

26 Marlin S D, Springer T A, Purified intercellular adhesion molecule-1 (ICAM-1) is a ligand for lymphocyte functionassociated antigen-1 (LFA-1). Cell 1987; 51: 813-9.

27 Staunton D E, Dustin M L Springer T A. Functional cloning of ICAM-2, a cell adhesion ligand for LFA-1 homologous to ICAM-1. Nature 1989; 339: 61-4.

28 Saito I, Terauchi K, Shimuta M, et al. Expression of celladhesion molecules in the salivary and lacrimal glands of Sjögren's syndrome. F Clin Lab Analysis 1993; 7: 180-7.

29 Pitzalis C, Kingsley G H, Haskard D, Panayi G S. The preferential accumulation of helper-inducer $T$ lymphocytes in inflammatory lesions: evidence for the regulation by selective endothelial and homotypic adhesion. Eur $\mathcal{f}$ Immunol 1988; 18: 1397-404. 